\title{
Rammed earth construction with granitic residual soils: the case study of northern Portugal
}

\author{
Rui. A. Silva ${ }^{\mathrm{a}, \dagger}$, Daniel V. Oliveira ${ }^{\mathrm{a}}$, Tiago F. Miranda ${ }^{\mathrm{b}}$, Nuno M. Cristelo ${ }^{\mathrm{c}}$, Maria C. \\ Escobar $^{\mathrm{a}}$, Edgar Soares $^{\mathrm{c}}$ \\ ${ }^{a}$ Department of Civil Engineering, ISISE, University of Minho, Guimarães, Portugal \\ ${ }^{b}$ Department of Civil Engineering, C-TAC, University of Minho, Guimarães, Portugal \\ ${ }^{c}$ School of Science and Technology, University of Trás-os-Montes e Alto Douro, Vila Real, \\ Portugal
}

\begin{abstract}
Building in unstabilised rammed earth results in low environmental impact. However, northern Portugal has not historical tradition with this technique, and thus the suitability of the local granitic residual soils is unknown. This paper presents an experimental investigation, where this possibility is assessed. The results showed that these soils are unsuitable, and that rammed earth construction is only feasible if these soils go through a stabilising process. The alkaline activation of fly ash was investigated as an environmentally friendly stabilisation technique, and it proved to be capable of improving the performance of rammed earth.
\end{abstract}

\section{Highlights:}

- $\quad$ The strength of unstabilised rammed earth built with granite residual soils is low.

- Stabilization is required to build rammed earth with granite residual soils.

- The alkaline activation of fly ash was tested as stabilisation technique.

- The alkaline activation improves the strength and durability of rammed earth.

Keywords: Rammed earth, granitic residual soil, sustainable construction, alkaline activation, fly ash

\section{INTRODUCTION}

In 1982 the World's population living in a house built with raw earth was of about one third [1], whereas nowadays is estimated to be of about one fourth [2]. Despite that, building with earth continues to be a popular solution for sheltering and housing in many countries around the world, especially in developing countries. In developed countries this practice has fallen into disuse over the past century, as consequence of the technological development and

\footnotetext{
${ }^{\dagger}$ Corresponding author: Department of Civil Engineering, University of Minho, Azurém, 4800-058 Guimarães, Portugal. Tel.: +351253 510 200; fax: +351253510217.

E-mail address: ruisilva@civil.uminho.pt
} 
extensive use of modern building materials (concrete and steel). Earthen materials are in general considered to be non-standard, since they are not produced according to industrialized processes [3]; in many cases these materials are produced on-site and their properties are extremely dependent on the characteristics of the available soil, which itself is a rather heterogeneous material. In addition, there are only few countries that have codes or standards for earth construction (e.g. New Zealand [4-6], Peru [7] and the USA [8]), which further discourages the option for this building solution where those are absent. However, the building industry has been recalling earth construction as a modern building solution due mostly to its recognized sustainability, low environmental impact, and good thermal and acoustic performance [9].

The earth construction concept includes several building techniques that have different constructive features, which depend mostly on cultural and social factors and on local limitations related with the characteristics of the available soils. In Portugal, there are present and widespread earth constructions erected according to three main building techniques: rammed earth ("taipa"), adobe and wattle-and-daub ("tabique"). Rammed earth, which consists in compacting moist soil by layers between a removable formwork to build monolithic walls, is found almost exclusively in southern Portugal. On the other hand, the traditional building stock of northern Portugal is mainly constituted by stone masonry dwellings, whose construction was supported by the great availability of this resource in the region. This type of construction has gradually been replaced, and nowadays the building industry is dominated by a solution consisting of a reinforced concrete framed structure with fired brick masonry infill and concrete slabs. According to Lourenço [10], the embodied energy of a $92 \mathrm{~m}^{2}$ house built resorting to this solution is more than the double of that of a solution constituted by exterior rammed earth walls, interior adobe walls and timber roof. Therefore, adopting rammed earth as a building solution in northern Portugal would probably contribute to a more sustainable building industry. However, this technique is historically almost absent from the region, which raises the question about the suitability of the typical and abundant granitic residual soils (GRS) from northern Portugal for unstabilised rammed earth (URE) construction.

Stabilising the soil chemically (e.g. by addition of cement) is an option that may allow the GRS to be used in rammed earth construction if they are not adequate for URE. However, the embodied energy and cost of rammed earth construction would increase substantially [1, 10], making this solution less competitive. 
Having the aforementioned in mind, an experimental program that included the assessment of four representative soils from northern Portugal was carried out, regarding their suitability for URE. In addition and as a consequence of the results observed for each soil, an alternative stabilisation technique based on alkaline activation of fly ash is proposed. This technique aims, in first instance, at reducing the environmental impact of stabilised rammed earth (SRE), by incorporating an industrial waste material (fly ash).

\section{RAMMED EARTH CONSTRUCTION IN PORTUGAL}

Rammed earth construction was extensively used in Portugal during the Islamic domination period (between $7^{\text {th }}$ and $13^{\text {th }}$ centuries), both to build military and civil constructions. The military constructions are mainly constituted by fortresses, which were firstly built between the 7th and 9th centuries. Currently, the castles of Silves and of Paderne, more than 800 years old, are live examples of such fortresses. The military rammed earth is in general stronger and more durable than civil rammed earth, since in general soil stabilised by addition of lime and natural pozzolans was frequently used in the first case [11]. On the other hand, the civil constructions were mainly built with URE, as lime is a resource that used to be too expensive and inaccessible for the majority of the population.

Until the 1950s, URE was the main building technique used in southern Portugal for sheltering, namely in Ribatejo, Alentejo and Algarve regions, which resulted in the geographical distribution of Fig. 1a [12]. Nowadays, this technique represents a very low percentage of new construction. Moreover, the few new rammed earth constructions are frequently built with SRE (by addition of cement or lime) and/or by embedding a reinforced concrete framed structure (Fig. 1b), which are procedures that aim at improving the structural behaviour, namely the seismic performance.

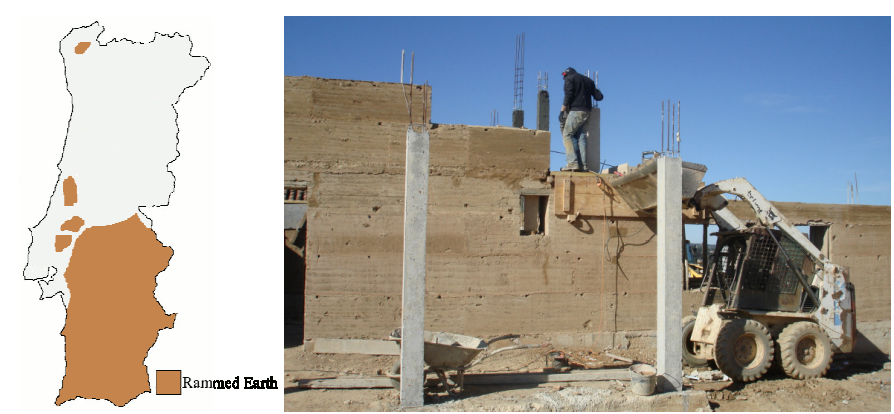

(a)

(b)

Fig. 1 - Rammed earth construction in Portugal: (a) geographical distribution; (b) new rammed earth house with embedded concrete structure (Odemira, Portugal). 
The traditional construction in northern Portugal is dominated by granite stone masonry. Regarding the earth construction techniques, the wattle-and-daub ("tabique") is the most common and was usually used to build partition walls of traditional stone masonry buildings [13]. Rammed earth constructions are almost absent from northern Portugal as there are only a few known cases reported in Viana do Castelo [12]. This absence can be explained by several factors, including: history and culture of the population, availability of stone, suitability of the soils for rammed earth construction, and climate and hazards of the region.

The fact that northern Portugal has not been under a real Islamic domination (unlike southern Portugal) may be pointed out as a reason to explain the absence of rammed earth from the region. Nevertheless, this technique is not strange to the northern neighbouring region of Galicia in Spain [14], which also has not been under Islamic domination.

The absence of rammed earth can also be explained by the great availability of granite and schist as building materials and by the unsuitability of the region's soils. The soils from northern Portugal are mainly saprolitic residual soils from granite rocks, which are weathered by high rainfall rates. In general, these soils are well graded in particle size distribution and have low plasticity indexes, and thus are usually classified as silty sands (SM) and clayey sands (SC). Mineralogically speaking, GRS are constituted mainly by silicates (in more than $65 \%$ ). The main silicate minerals are quartz, which is very slowly affected by weathering processes, and feldspars, which are continuously transformed into kaolinite, and mica minerals [15]. However, and according to Correia and Merten [12], the rammed earth walls of dwellings from Alentejo built with soils resulting from the weathering of schist are those presenting better mechanical properties. These soils are commonly found in the region and present relatively high clay content and elongated-shaped coarse particles, which result in URE walls with good cohesion and improved interlocking. Moreover, the same authors [12] highlighted that rammed earth walls built using soils with high content of round shaped quartz particles show high tendency to disaggregate. Unfortunately, the GRS characteristics seem to fit within this last case, which means that rammed earth walls built with this type soil may show low strength and disaggregation problems. Furthermore, an URE wall built with a soil with such characteristics may have durability problems when facing the climate of northern Portugal, which is characterized by high annual rainfall rates [16].

The seismic hazard of northern Portugal combined with the generally accepted poor seismic performance of earth constructions could be indicated as another reason to explain the absence of the rammed earth technique. Nevertheless, the seismic hazard of northern Portugal (reference peak ground acceleration between $0.5 \mathrm{~m} / \mathrm{s}^{2}$ and $0.8 \mathrm{~m} / \mathrm{s}^{2}$ ) is less important than that 
of southern Portugal (reference peak ground acceleration between $1.5 \mathrm{~m} / \mathrm{s}^{2}$ and $2.5 \mathrm{~m} / \mathrm{s}^{2}$ ), where the rammed earth constructions represent a significant part of the building stock. Thus, the unsuitability of the GRS for URE construction seems to be the only reason behind the non-existence of a spread out of rammed earth construction in northern Portugal. This topic is discussed in the following section on the basis of an experimental program.

\section{SUITABILITY OF GRS FOR URE CONSTRUCTION}

\subsection{Methodology}

An exhaustive review on regulating and guideline documents for earth construction is presented in Delgado and Guerrero [17], whereas the current paper presents a practical approach of those documents applied to the case study of northern Portugal. However, and roughly speaking, the decision on the soil suitability for rammed earth construction is based on the assessment of the soil properties or/and on the performance of rammed earth specimens prepared with that soil. In general, the aforementioned documents outline limit properties of the soil, such as those regarding the texture, consistency, organic content, binding force and compactability, and are determined by means of expeditious and laboratory tests. Thus, if the soil properties fit within limit values, it is assumed that the respective rammed earth will present the required performance. However, the correlation existing between the soil properties and the performance of the respective rammed is not clear and does not account the immense diversity existing between soils. This may result in misleading suitability assessments, whose reliability would require testing, in laboratory, the performance of manufactured rammed earth specimens. In this case, the compressive strength and the water erosion resistance of rammed earth are frequently adopted as performance indicators for strength and durability. Furthermore, some tests referred in the aforementioned documents also serve to determine important parameters featuring the building process.

The assessment of the suitability for URE construction was carried out on four GRS collected from different locations in northern Portugal. Soils S1 (Azurém), S2 (Pencelo) and S3 (Louredo) were collected from the municipality of Guimarães, while S4 (Barqueiros) was collected from the municipality of Barcelos. All the samples were collected superficially (between $5 \mathrm{~cm}$ and $20 \mathrm{~cm}$ deep). The properties of the soils were assessed by means of frequently adopted expeditious and laboratory tests, while the performance of rammed earth manufactured with the soils was assessed by means of tests carried out in laboratory. 


\subsection{Soil assessment}

The assessment of the soils for rammed earth construction was carried out both by means of expeditious and laboratory tests. By definition, expeditious tests are of simple execution and only require common tools, making them prone to be carried out on-site. These tests are essentially focused in evaluating the properties of soil in a qualitative way, while giving indications on the suitability of the soil. Despite the qualitative aspect of the expeditious tests results, they still assume great importance in documents on earth construction. This is explained by the fact that, in many situations, expeditious tests are the only available alternative and, in addition, they are able to provide important parameters featuring the building process. For instance, the drop test is an expeditious test frequently used (at least in Portugal) to determine the compaction water content.

The laboratory tests are in general more accurate and rigorous than those expeditious. However, their execution requires more resources (tools, equipment, expertise, funding, etc.) that are not always available, and typically include the geotechnical characterization of the soils. Table 1 outlines the expeditious and laboratory tests preformed to assess the properties of the soils, and thus the suitability for URE. It is worth to mention that these tests are frequently used in practice.

Table 1 - Expeditious and laboratory tests used to characterize the GRS soils.

\begin{tabular}{lll}
\hline Test & Assessed property & Reference \\
\hline Visual inspection & Texture/organic matter & ASTM D 2488 [18] \\
Sedimentation & Texture & HB 195 [19] \\
Ribbon test & Texture (binding force) & HB 195 [19] \\
Drop test & Compaction/texture & NZS 4298 [5] \\
Dry strength test & Texture & Houben and Guillaud [1] \\
Particle size distribution & Texture & LNEC E 196 [20] \\
Atterberg limits & Plasticity & NP 143 [21] and ASTM D 4943 [22] \\
Standard Proctor & Compaction & LNEC E 197 [23] \\
\hline
\end{tabular}

\subsubsection{Visual inspection}

The visual inspection of the soils was carried out based in ASTM D 2488 [18], which allowed evaluating more objectively properties such as colour, angularity, shape and odour of the particles. Generically speaking, the soils present light tones of colours such as grey and yellow. In terms of angularity, the particles of the soils are sub-angular, but the soil S4 also presents sub-rounded particles. All soils have particles that are neither elongated nor flat in terms of shape, whereby URE walls built with these soils are expected to have lower mechanical properties than those built with schist residual soils from southern Portugal (see 
section 2). Finally, no odour indicating the presence of organic matter was identified in the samples.

\subsubsection{Sedimentation test}

The sedimentation test allows obtaining qualitatively the proportions between the different size fractions composing the soils, by visually identifying the respective sedimentation layers (Fig. 2a). The results of the tests are presented in Fig. $2 \mathrm{~b}$ for all soils, where the clay and silt fractions are grouped. Soils S1, S2 and S3 present similar proportions between fractions. However, their clay and silt content seem to be low for rammed earth construction when compared with the recommended values according to Houben and Guillaud [1] (between 21\% and $37 \%$ ) or adequate when compared with those of HB 195[19] (between 15\% and 50\%), but by a minor margin. On the other hand, soil S4 presents the highest content of clay and silt, which is within the recommended values. It should be noted that results of this soil are affected by the observed flocculation of the clay fraction, which occupies a much larger volume than in its deflocculated state.

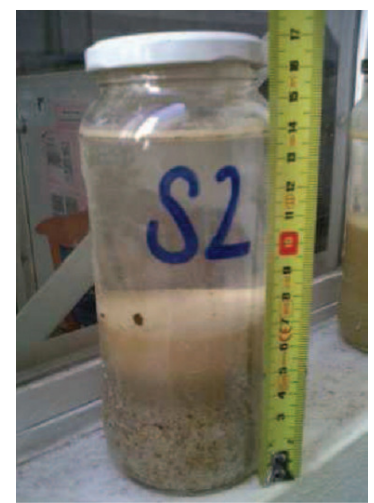

(a)

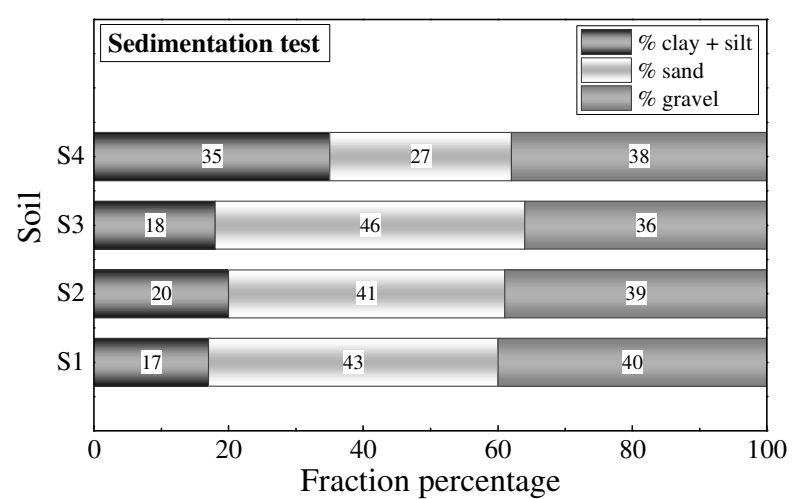

(b)

Fig. 2 - Sedimentation test: (a) soil S2 sedimentation flask; (b) results of all tests.

\subsubsection{Ribbon test}

The ribbon test also allows assessing qualitatively the proportions between the different size fractions composing a soil. Regarding the results, soils S1, S2 and S3 present very low clay content, since it was not possible to roll them into the shape of a sausage (Fig. 3a). In practical terms, this may mean that their clay content is insufficient to produce earthen materials with adequate strength and durability.

average length of the ribbon was of about $45 \mathrm{~mm}$, which according to HB 195 [19], makes this soil suitable for stabilised compressed earth blocks and for rammed earth construction. 


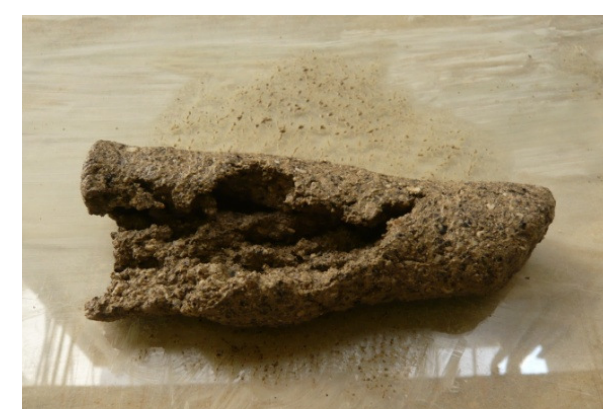

(a)

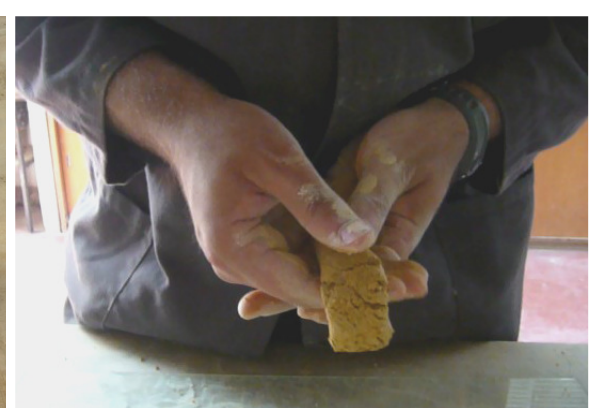

(b)

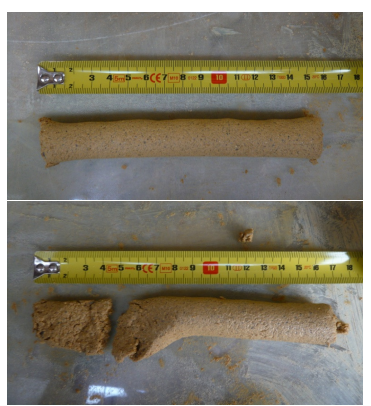

Fig. 3 - Ribbon test: (a) soil S1; (b) soil S4.

In the case of soil S4, it was possible to roll the sausage and perform the test (Fig. 3b).The

\subsubsection{Drop test}

This test requires several trials while adjusting the water content of the mixture to obtain the correct state of the ball after impact on the ground. Fig. 4 presents the three possible states occurring within the tests. After obtaining a successful trial (i.e. the ball crumbled partly with minor cracks - Fig. 4a), the water content of the ball (DTWC) was measured for each soil and later on compared with OWC in section 3.2.8 (Table 4). It should be mentioned that moulding the ball was difficult for soils S1, S2 and S3, thus confirming the low clay content discussed in the previous tests.

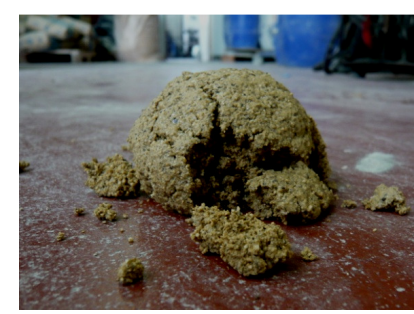

(a)

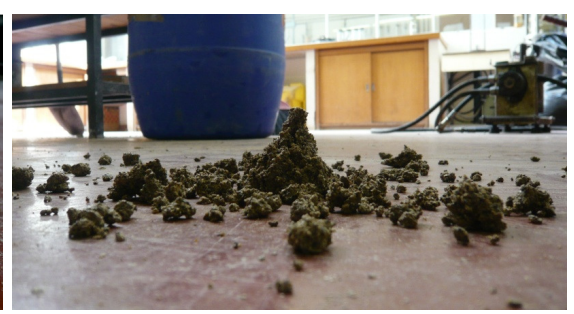

(b)

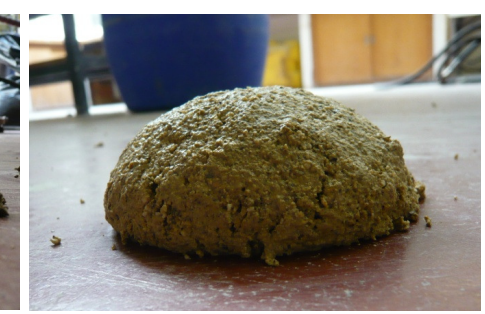

(c)

Fig. 4 - Possible states of the ball after impact: (a) crumble partly with minor cracks, (b) completely crumbled; (c) flattened.

\subsubsection{Dry strength test}

The dry strength test was carried out on dry soil (fraction below $0.425 \mathrm{~mm}$ ) pats with $4 \mathrm{~cm}$ diameter and $1 \mathrm{~cm}$ thickness (Fig. 5). The test was carried out by breaking the specimens and crushing them between the thumb and forefinger, and the results were interpreted according to Houben and Guillaud interpretation [1]. Soils S1, S2 and S3 have low dry strength, which means that their fine fraction is mainly constituted by silt and fine sand. The soil S4 presents moderate dry strength, which evidences the higher clay content of this soil when compared with the remaining three, and thus rammed earth prepared with this soil is expected to result in a material with higher cohesion. 

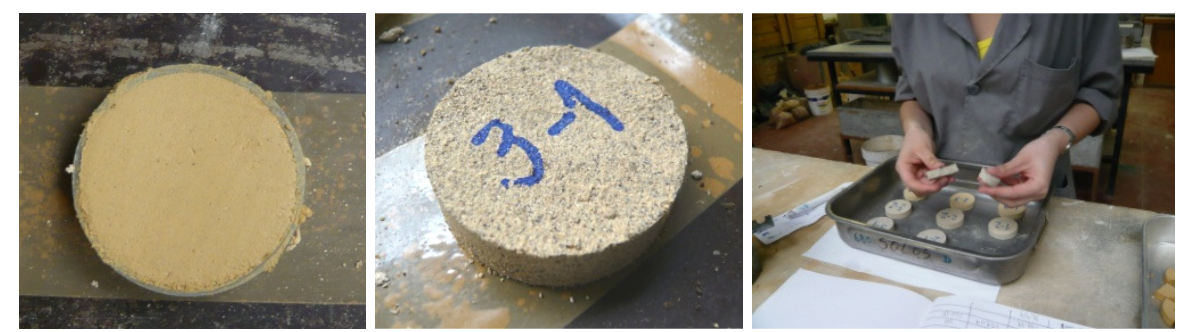

Fig. 5 - Dry strength test.

\subsubsection{Particle size distribution analysis}

Sieving and sedimentation analyses were carried out in order to quantify the proportions of all size fractions composing the soils, which are presented in Table 2. The particle size distribution (PSD) curves were also plotted and compared with the envelope of typical GRS from northern of Portugal [15] to assess their representativeness, see Fig. 6. The soils S1, S2 and S3 have clay and silt contents that are within the envelope, while the clay content of soil S4 is slightly higher than that of the envelope, and thus it represents GRS with high clay content. Moreover, soil S4 clay content is at least twice as large as that of the other soils, which is in agreement with the observations taken from the sedimentation test.

Table 2 - Particles size fractions of the assessed soils (according to the size fractions usually adopted in earth construction).

\begin{tabular}{lllll}
\hline Soil & Clay $(\%)$ & Silt $(\%)$ & Sand $(\%)$ & Gravel $(\%)$ \\
\hline S1 & 6 & 14 & 45 & 35 \\
S2 & 5 & 15 & 59 & 21 \\
S3 & 4 & 14 & 60 & 22 \\
S4 & 12 & 12 & 53 & 23 \\
\hline (clay $<0.002 \mathrm{~mm} / 0.002 \mathrm{~mm} \leq$ silt $<0.060 \mathrm{~mm} / 0.060 \mathrm{~mm} \leq$ sand $<2.0 \mathrm{~mm} / 2.0 \mathrm{~mm} \leq$ gravel < 20 \\
mm)
\end{tabular}

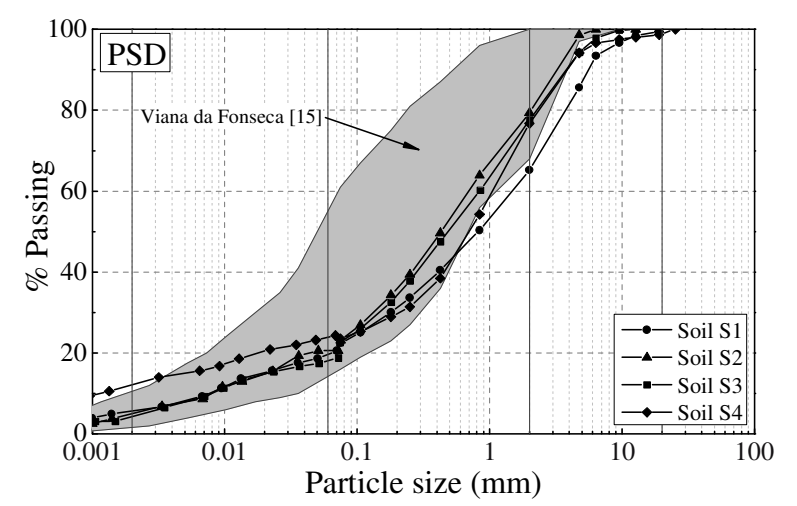

Fig. 6 - Comparison between the PSD curves of the soils and the envelope presented by Viana da Fonseca [15] for GRS from northern Portugal.

The HB 195[19] defines the suitability of the soils for URE construction by limiting the clay (5-20\%), silt (10-30\%) and sand plus gravel (45-75\%) contents. According to this document, the soils are considered unsuitable, since their sand plus gravel contents are excessively high, 
but the clay and silt contents are within the limits. Moreover, the PSD curves of the soils were plotted against two recommend PSD envelopes for URE construction in Fig. 7 [1, 24]. Despite of some differences between the envelopes, both agree that soils S1, S2 and S3 lack in clay content. This means that an URE wall built with these soils may not present adequate strength and durability, because there is insufficient clay to hold together the coarser particles (binder function). On the other hand, the higher clay content of the soil S4, which is within the envelopes, is expected to provide URE walls with superior strength and durability. It should be noted that the addressed envelopes are not part of a standard, whereby they should not taken as being restrictive for the soil suitability, but it is worth to mention that the envelope presented by LNEC [24] is with respect to the Portuguese case.

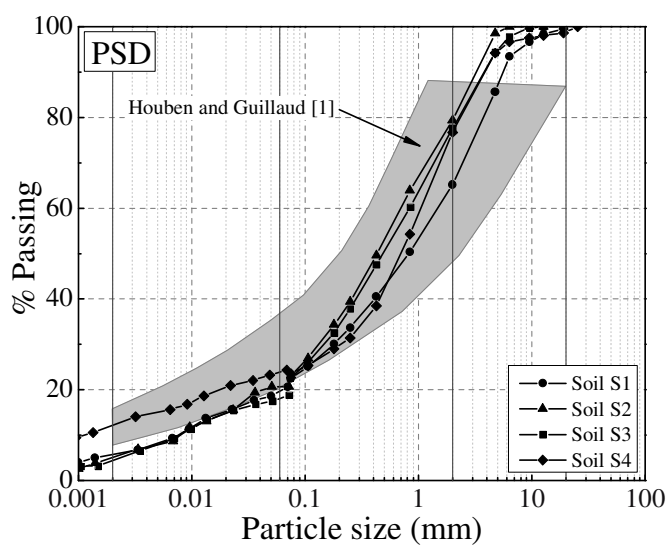

(a)

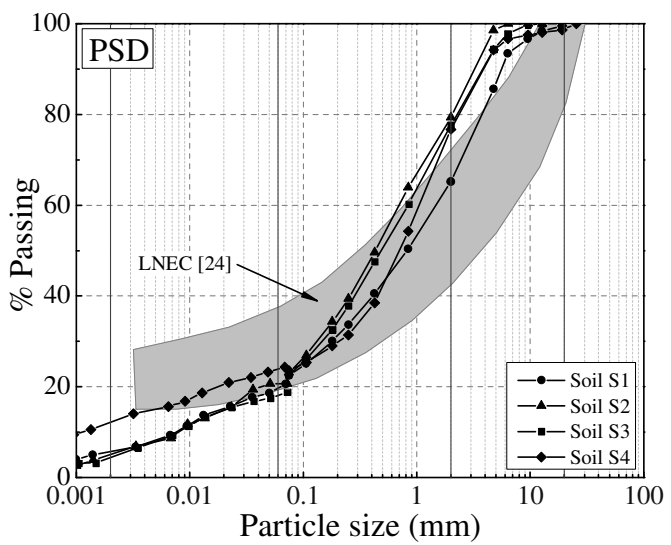

(b)

Fig. 7 - Comparison between the PSD curves of the soils and the envelopes for rammed earth construction recommended by: (a) Houben and Guillaud [1]; (b) Portuguese National Laboratory of Civil Engineering [24].

\subsubsection{Atterberg limits}

The plastic limit (PL), liquid limit (LL) and shrinkage limit (SL) were determined for each soil and the results are presented in Table 3, as well as the respective unified soil classification system (USCS) [25].

Table 3 - Atterberg's limits of the soils and respective USCS classification.

\begin{tabular}{lllllll}
\hline Soil & LL $(\%)$ & PL $(\%)$ & PI $(\%)$ & SL $(\%)$ & SI $(\%)$ & USCS classification \\
\hline S1 & 34 & - & - & 27 & 7 & Silty sand (SM) \\
S2 & 27 & - & - & 23 & 4 & Silty sand (SM) \\
S3 & 28 & - & & 26 & 2 & Silty sand (SM) \\
S4 & 30 & 19 & 11 & 22 & 8 & Clayey sand (SC) \\
\hline
\end{tabular}

The PL could not be obtained for soils S1, S2 and S3, whereby they are classified as nonplastic soils. As a consequence, these soils would probably result in cohesionless URE, whereby they seem to be unsuitable. Soil S4, on the other hand, is considered to be a medium cohesive soil, and presents LL and PI within the recommended limits by HB 195[19], which are, respectively, below $35-45 \%$ and $10-30 \%$. The low values obtained for the shrinkage 
index (SI) of the soils indicate that these have low shrinkage/swelling characteristics, which constitutes a good feature when addressing rammed earth construction.

\subsubsection{Standard Proctor test}

The compaction properties of the soil are very important in rammed earth construction because there is a direct relationship between dry density and compressive strength of the material; the denser the material, the higher is its strength. The standard Proctor test is in general preferred to the modified Proctor, since the compaction energy of traditional rammed earth is closer to that of the first test [1]. The results are summarized in Table 4 in terms of maximum dry density, optimum water contents (OWC). Soils S1, S2 and S3 are shown to have similar OWC, however they present rather different maximum dry densities, where S1 is the densest and the S3 the least dense. Soil S4 is even denser than the other three soils and has a lower OWC, which in practical terms may mean that its use would result in rammed earth with better mechanical performance. According to Doat et. al. [26], soil S3 is expected to result in a fairly poor earthen material $\left(1.65<\gamma_{d}<1.76 \mathrm{~g} / \mathrm{cm}^{3}\right)$, while soils $\mathrm{S} 1, \mathrm{~S} 2$ and S4 are expected to be very satisfactory $\left(1.76<\gamma_{d}<2.10 \mathrm{~g} / \mathrm{cm}^{3}\right)$ in terms of performance.

Table 4 -Compaction properties of the soils and compaction water content obtained by drop test (DTWC).

\begin{tabular}{lllll}
\hline Soil & $\gamma_{d \max }\left(\mathrm{g} / \mathrm{cm}^{3}\right)$ & OWC $(\%)$ & DTWC $(\%)$ & $G_{s}$ \\
\hline S1 & 1.92 & 12 & 18 & 2.69 \\
S2 & 1.84 & 12 & 18 & 2.63 \\
S3 & 1.71 & 12 & 20 & 2.62 \\
S4 & 2.01 & 10 & 10 & 2.64 \\
\hline
\end{tabular}

In addition, it should be noted that the drop test provides a good approximation for the OWC of soil S4, but not for the other soils. This result is probably affected by the low clay content of soils S1, S2 and S3, which difficult the execution of the drop test, and whereby this test may not be suitable for this type of soils.

\subsection{URE performance}

The suitability of a soil for URE is ultimately decided by assessing the performance of the earthen material manufactured with it, and then verify if the project or standard requirements are satisfied. Thus, the performance of the URE manufactured with the four assessed soils was tested by means of compression tests and of the Geelong test.

\subsubsection{Compression test}

The compressive strength of rammed earth prepared with the four soils was assessed by means of small scale compression tests. The specimens consisted of three-layered cylinders 
with dimensions of $100 \mathrm{~mm}$ diameter by $200 \mathrm{~mm}$ height, which were compacted with the maximum dry density and OWC obtained from the Proctor test. Specimens were then stored in a room with constant temperature $\left(20^{\circ} \mathrm{C}\right)$ and relative humidity $(57.5 \%)$ and were tested after attaining equilibrium water content (testing age between 27 and 35 days). The tests were carried out under monotonic displacement control at a rate of $3 \mu \mathrm{m} / \mathrm{s}$ and the vertical deformation at the middle third of each specimen was measured by means of three LVDTs disposed radially (see Fig. 8). It should be noted that this procedure was adopted since there are no standards specifically developed for testing rammed earth.

Table 5 presents the results of the compression tests in terms of compressive strength $\left(f_{c, U}\right)$ and Young's modulus $\left(E_{0, U}\right)$ computed between $5 \%$ and $30 \%$ of the compressive strength by linear fitting of the respective stress-strain curve. The values given in Table 6 are average results from 3 specimens.

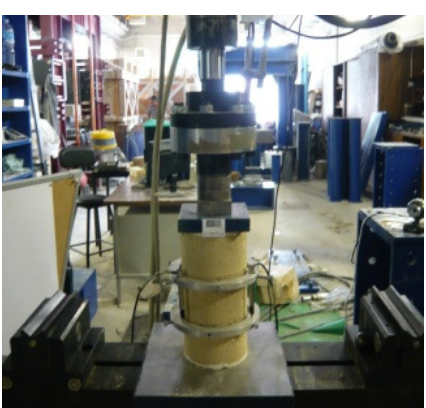

(a)

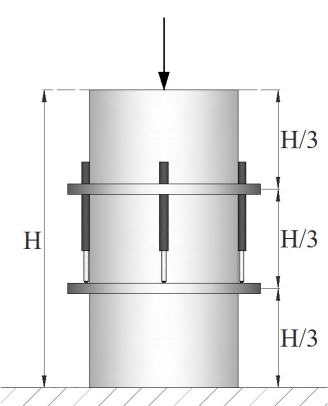

(b)

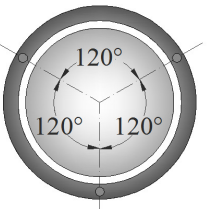

Fig. 8 - Compression tests: (a) test setup; (b) LVDTs configuration.

Table 5 - Average results of the compression tests carried out on URE specimens.

\begin{tabular}{lll}
\hline Soil & $f_{c, U}\left(\mathrm{~N} / \mathrm{mm}^{2}\right)$ & $E_{0, U}\left(\mathrm{~N} / \mathrm{mm}^{2}\right)$ \\
\hline S1 & 0.41 & 100.0 \\
S2 & 0.25 & 80.5 \\
S3 & 0.43 & 70.6 \\
S4 & 0.41 & 221.6 \\
\hline
\end{tabular}

Soil S2 presents a compressive strength $\left(0.25 \mathrm{~N} / \mathrm{mm}^{2}\right)$ remarkably lower than the other soils, which is of about $0.42 \mathrm{~N} / \mathrm{mm}^{2}$. However, it should be noted that the compressive strength of all soils is in general very low when compared with the minimum requirements of some documents concerning rammed earth construction (see Table 6).

Table 6 - Required compressive strength according to documents regulating rammed earth construction.

\begin{tabular}{|c|c|c|}
\hline Document & Country & Required $f_{c}\left(\mathrm{~N} / \mathrm{mm}^{2}\right)$ \\
\hline HB 195 [19] & Australia & $\geq 2^{a}$ \\
\hline NMAC 14.7.4 [8] & USA (New Mexico) & $>2.1^{\mathrm{b}}$ \\
\hline SNZ 4298 [5] & New Zealand & $>1.3^{\mathrm{c}}$ \\
\hline
\end{tabular}


The least demanding case corresponds to the New Zealand standard [5], whose required compressive strength for standard grade rammed earth constructions (when corrected by the height-to-thickness factor of the tested specimens provided in the standard) is of about $1.14 \mathrm{~N} / \mathrm{mm}^{2}$.

\subsubsection{Geelong test (durability)}

The Geelong test (also known as drip test) was used to test the durability performance of URE manufactured with the soils. The test was carried out on cubic specimens (one per soil), with dimensions of 150x150x $150 \mathrm{~mm}^{3}$, compacted in three layers with the maximum dry density and OWC obtained from the Proctor test. The specimens dried in a room with controlled temperature $\left(20^{\circ} \mathrm{C}\right)$ and relative humidity $(57.5 \%)$ and were tested with 21 days of age. The pitting depth and depth of moisture penetration were measured in each test (Fig. 9).

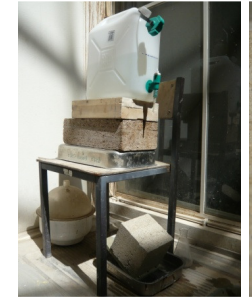

(a)

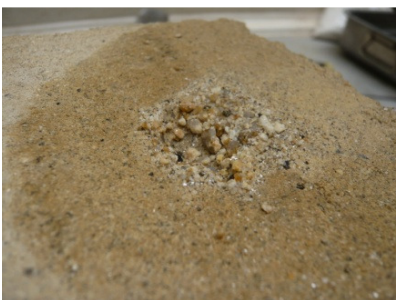

(b)

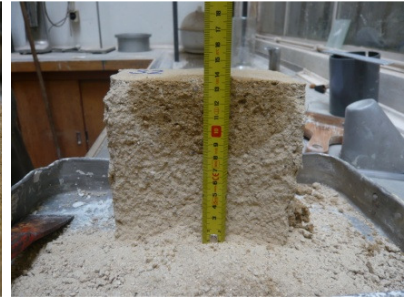

(c)

Fig. 9 - Geelong test: (a) test setup; (b) pitting depth; (c) depth of moisture penetration of soil specimen S2.

The results are given in Table 7, where the pitting depth is classified as an erodibility index according to NZS 4298 [5]. It should be noted that the moisture penetration depth of all soils is less than $120 \mathrm{~mm}$, as it is required by the standard. The use of these soils in unplastered URE walls is limited to situations that require erodibility indexes equal or higher than 3 , in the case of soils S1, S2 and S3, and than 2, in the case of soil S4 [4]. The HB 195 [19] has a more practical approach of this test, where according to the resulting erodibility indexes, soils $\mathrm{S} 1, \mathrm{~S} 2$ and S3 can be used in protected external walls and soil S4 in exposed external walls.

Table 7 - Results of the Geelong test.

\begin{tabular}{llll}
\hline Soil & Pitting depth $(\mathrm{mm})$ & Erodibility index & Depth of moisture penetration $(\mathrm{mm})$ \\
\hline S1 & 6 & 3 & 51 \\
S2 & 9 & 3 & 58 \\
S3 & 5 & 3 & 40 \\
S4 & 3 & 2 & 20 \\
\hline
\end{tabular}

\subsection{Remarks}

The expeditious tests allowed characterizing qualitatively properties of the tested GRS, considered relevant for their suitability for URE construction, and whose findings can be generalized as follows: (i) absence of organic matter observed in the visual inspection; (ii) 
low clay content (except soil S4) observed in the sedimentation, ribbon, drop and dry strength tests. Regarding the geotechnical characterization of the soils, the PSD analysis of the soil is the most relevant when referring to the suitability for URE construction. In this respect, all the soils, except S4, present clay contents that are below or close to the inferior limit of recommended ranges. Generally speaking, the expeditious and laboratory tests indicated that soils S1, S2 and S3 are unsuitable for URE construction, as was confirmed by their low mechanical performance. On the other hand, the assessment of soil S4 indicated that it may be suitable for URE, but the compressive strength was rather low, which makes it unsuitable. Moreover, it is worth to mention that that the drop test seems not to be adequate to estimate OWC of GRS upon the compaction of the rammed earth.

\section{SRE BY ALKALINE ACTIVATION OF FLY ASH}

Chemical stabilisation can be used to improve the performance of rammed earth built with GRS, and thus making it a feasible building solution. Regarding the typical low clay content of GRS, the addition of cement seems to be an efficient stabilisation solution. However, the addition of cement results in an important increase of the embodied energy of rammed earth walls [10]. For example, Lax [27] demonstrates that for a specific case, the embodied energy in SRE with $8 \%$ of cement is 1.84 times higher than in URE. In order to try to mitigate the environmental impact of SRE built with GRS, the authors have been developing an alternative stabilisation solution, which consists in the addition of a geopolymeric binder obtained from the alkaline activation of fly ash.

\subsection{Fundamentals on alkaline activation}

Alkaline activation consists in a reaction between alumina-silicate materials and alkali or alkali earth substances, namely: $\mathrm{ROH}, \mathrm{R}(\mathrm{OH})_{2}, \mathrm{R}_{2} \mathrm{CO}_{3}, \mathrm{R}_{2} \mathrm{~S}, \mathrm{Na}_{2} \mathrm{SO}_{4}, \mathrm{CaSO}_{4} \cdot 2 \mathrm{H}_{2} \mathrm{O}$, $\mathrm{R}_{2} \cdot(\mathrm{n}) \mathrm{SiO}_{2}$, in which $\mathrm{R}$ represents an alkaline ion like sodium $\left(\mathrm{Na}^{+}\right)$or potassium $\left(\mathrm{K}^{+}\right)$, or an alkaline earth ion like calcium $\left(\mathrm{Ca}^{2+}\right)$. It can be described as a polycondensation process, in which the silica $\left(\mathrm{SiO}_{2}\right)$ and alumina $\left(\mathrm{AlO}_{4}\right)$ tetrahedra interconnect and share the oxygen ions. The resulting polymeric structure of $\mathrm{Al}-\mathrm{O}-\mathrm{Si}$ bonds is the main structure of the hardened geopolymer matrix, which is very similar, at a molecular level, to natural rocks, sharing their stiffness, durability and strength. This technique has been recently studied in the manufacture of mortars and concrete [28], which present enhanced environmental impact and durability over those manufactured with ordinary Portland cement [29]. 
Fly ash is a by-product from the combustion of coal in power stations and is one of many possible prime sources of silica and alumina in the alkaline activation reactions [29]. The alkaline activation of fly ash has been recently studied as a soil stabilisation technique, with promising results [30-31]. In this type of application, the geopolymeric binder is mixed with the soil and upon hardening it forms a matrix that involves and binds the particles, forming a structured material capable of delivering higher strength levels than those of the original soil. The stabilisation of rammed earth by alkaline activation of fly ash was recently introduced in Cristelo et. al. [32], which presented a composition study using the soil S1 here described, and where the compressive strength was the control parameter. A low calcium content fly ash (type F) was used, activated with a solution of sodium silicate and sodium hydroxide. The effect of several variables was analysed, such as: maximum soil particle size, liquid:solid ratio, activator concentration, $\mathrm{Na}_{2} \mathrm{O}$ :ash ratio, and the effects of additives such as hydrated lime, sodium chloride and concrete superplasticizers. The main finding of this study was the great increase in strength promoted by the geopolymeric binder, even in the compositions with the lowest fly ash content (about $15 \%$ in wt.). The compressive strength of the tested mixtures varied between $3 \mathrm{~N} / \mathrm{mm}^{2}$ and $23 \mathrm{~N} / \mathrm{mm}^{2}$, when cured for periods between 1 and 7 days at $60^{\circ} \mathrm{C}$. These values are significantly higher than those required for rammed earth construction. This means that the content of geopolymeric binder can be further decreased in order to promote higher sustainability and lower cost of this stabilisation solution in SRE construction. Therefore, the major contribution of the present paper, relatively to [32], is the use of lower fly ash contents and the curing at ambient temperature.

\subsection{Materials and tested compositions}

The alkaline activation of fly ash by a sodium silicate/sodium hydroxide activator was tested on soil S3, aiming at improving its performance for rammed earth construction. This soil was preferred since it could be obtained in the large quantities required to build the tested specimens (about $1000 \mathrm{~kg}$ ). The formulation of the tested mixtures was based on the aforementioned considerations regarding the experimental research presented in Cristelo et. al. [32]. Therefore, the geopolymeric binder content was reduced to values similar to those usually used in the construction of SRE with cement (between 3 and $10 \mathrm{wt} . \%$ ), by fixing the fly ash percentage in $2.5 \%, 5 \%$ and $7.5 \%$ of the solid phase weight. Table 8 presents the composition of the tested mixtures. It should be noted that the activator constitutes all the liquid phase of the mixtures, and thus the activator/solids ratio assumed a fixed value, slightly inferior to the OWC of the original soil. 
Table 8 - Composition of the tested mixtures.

\begin{tabular}{llllll}
\hline Mixture & $\begin{array}{l}\text { Ash/soil } \\
\text { (solids wt.\%) }\end{array}$ & $\begin{array}{l}\text { Activ./solids ratio } \\
\text { (wt.) }\end{array}$ & $\begin{array}{l}\text { Activ./ash ratio } \\
\text { (wt.) }\end{array}$ & $\begin{array}{l}\text { Silic./hydro. } \\
\text { (wt.) }\end{array}$ & $\begin{array}{l}\text { NaOH sol. concent. } \\
\text { (molal) }\end{array}$ \\
\hline GSRE_2.5 & $2.5 / 97.5$ & 0.118 & 4.72 & $1: 1$ & 5 \\
GSRE_5.0 & $5.0 / 95.0$ & 0.118 & 2.36 & $1: 1$ & 5 \\
GSRE_7.5 & $7.5 / 92.5$ & 0.118 & 1.57 & $1: 1$ & 5 \\
\hline
\end{tabular}

The fly ash was obtained from a Portuguese thermo-electric plant, and is characterized mainly by its low calcium content (enabling it to be classified as type F) and by the $74 \%$ of mass available for dissolution (Si plus $\mathrm{Al}$ ). The sodium silicate was acquired in solution form, with a density of $1.45 \mathrm{~g} / \mathrm{cm}^{3}$, a sodium oxide $\left(\mathrm{Na}_{2} \mathrm{O}\right)$ content of $13 \%$ and a $\mathrm{SiO}_{2}: \mathrm{Na}_{2} \mathrm{O}$ ratio of about 2. The sodium hydroxide was originally acquired in flake form, with a density of $2.13 \mathrm{~g} / \mathrm{cm}^{3}$ at $20^{\circ} \mathrm{C}$, and $95-99 \%$ purity, and was dissolved in water to achieve a concentration of 5 molal before being mixed with the sodium silicate to compose the activator.

\subsection{SRE performance}

The aforementioned mixtures were used to prepare different types of SRE specimens, which had their performance tested by means of compression, diagonal-compression and spray tests. It should be noted that all specimens were compacted in such a way that their density would be just slightly lower than the maximum dry density obtained with the Proctor test, and it was considered that all the liquid phase would be part of the hardened specimens (no losses by evaporation).

\subsubsection{Compression test}

The compressive strength was tested on three cylindrical specimens (per mixture) similar to those used for testing the URE performance (section 3.3.1), which were wrapped in plastic sheet after demoulding and were cured at room temperature of about $20 \pm 2^{\circ} \mathrm{C}$ for 28 days. The testing procedure was the same used for the URE specimens (Fig. 10a). Table 9 presents the average results of the tests in terms of compressive strength $\left(f_{c, S}\right)$ and Young modulus $\left(E_{0, S}\right)$, as well as the respective improvement relative to the URE specimens.

Table 9 - Average results of the compression tests on SRE specimens.

\begin{tabular}{lllll}
\hline Mixture & $f_{c S}\left(\mathrm{~N} / \mathrm{mm}^{2}\right)$ & $f_{c S} / f_{c U}$ & $E_{0, S}\left(\mathrm{~N} / \mathrm{mm}^{2}\right)$ & $E_{0, S} / E_{0, U}$ \\
\hline URE & 0.43 & 1 & 70.6 & 1 \\
GSRE_2.5 & 0.72 & 1.7 & 1145 & 16 \\
GSRE_5.0 & 0.93 & 2.2 & 1168 & 17 \\
GSRE_7.5 & 1.09 & 2.5 & 2858 & 40 \\
\hline
\end{tabular}

The alkaline activation of fly ash resulted in a substantial increase in stiffness of soil S3 for all mixtures. The strength increase is also an evident result, since the compressive strength of the 
SRE specimens ranges between 1.7 and 2.5 times higher than that of the URE specimens. However, the strength improvement presented by the mixtures was not sufficient to exceed the required performance for rammed earth construction (Table 6). The obvious solution to achieve adequate strength would be the incorporation of higher fly ash contents, since several studies have shown that the higher the ash content, the higher is the strength [30-32]. However, it should be noted that the same referenced studies have concluded that a curing period of 28 days is not enough to allow the complete development of the geopolymeric matrix, responsible for the strength increase of these materials. This is because the hardening kinetics of fly ash geopolymeric binders, especially under mild ambient temperatures, is known to be slow, especially when compared with that of Portland cement [30, 33]. Therefore, a significantly higher strength levels can be expected for these mixtures, providing some more curing time is allowed. Ongoing tests by the authors seem to show that the average compressive strength at 90 days can double the values obtained at 28 days, but further tests are required to evaluate this effect. Moreover, the compaction of SRE specimens required less effort than URE specimens, which means that the density of rammed earth constructed with stabilised soil can easily be higher than that obtained using non-stabilised soil. This is a consequence of the addition of finer particles (fly ash), which modifies the PSD.

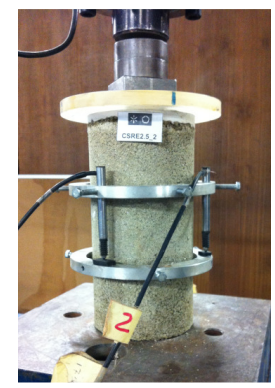

(a)

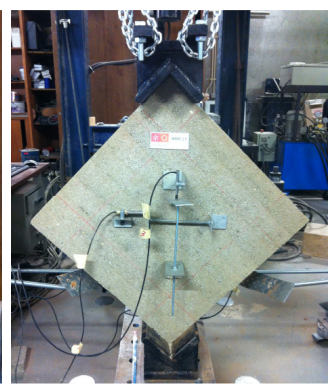

(b)

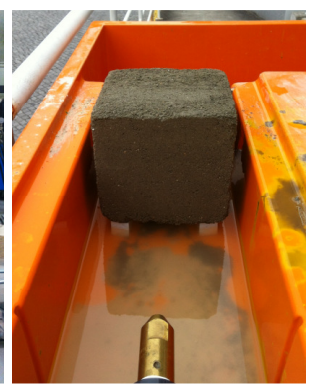

(c)

Fig. 10 - Tests carried out on SRE specimens: (a) compression test; (b) diagonal compression test; (c) spray test.

\subsubsection{Diagonal compression test}

The shear behaviour of SRE specimens was assessed by means of diagonal compression tests on 550x550x200 $\mathrm{mm}^{3}$ wallets (one per mixture) compacted in 9 layers with similar thickness (Fig. 10b). The specimens were demoulded immediately after compaction and were let to cure uncovered at room temperature of about $22 \pm 2^{\circ} \mathrm{C}$ for 46 days. The testing procedure was similar to that of ASTM E519 [34], which consisted in applying a monotonic displacement of $4 \mu \mathrm{m} / \mathrm{s}$ and using $100 \mathrm{~mm}$ length supports. It is worth to mention that, in addition to the SRE wallets, a URE wallet was also prepared, but it could not be tested since it disaggregated while being handled, showing the lack of cohesion of the material. The vertical and horizontal 
deformations of the specimens were measured in both faces, using four LVDTs, located in the middle third of both diagonals of each side.

The results of the diagonal compression tests are presented in Table 10, in terms of shear strength $\left(f_{s, S}\right)$ and shear modulus $\left(G_{0, S}\right)$, which was computed between $5 \%$ and $30 \%$ of the shear strength by linear fitting of the respective shear stress-shear distortion curve. These two parameters are shown to increase with the fly ash content. The shear strength was higher than that reported for URE $\left(0.037 \mathrm{~N} / \mathrm{mm}^{2}\right)$ [35] and significantly higher than that reported for adobe masonry $\left(0.022-0.032 \mathrm{~N} / \mathrm{mm}^{2}\right)$ [35-36].

Table 10 - Results of the diagonal compression tests.

\begin{tabular}{lcc}
\hline Mixture & $f_{s, S}\left(\mathrm{~N} / \mathrm{mm}^{2}\right)$ & $G_{0, S}\left(\mathrm{~N} / \mathrm{mm}^{2}\right)$ \\
\hline URE & \multicolumn{2}{c}{ Wallet disaggregated } \\
GSRE_2.5 & 0.14 & 576 \\
GSRE_5.0 & 0.14 & 505 \\
GSRE_7.5 & 0.18 & 620 \\
\hline
\end{tabular}

The shear stress-shear distortion curves of the specimens are presented in Fig. 11, where similar shapes can be observed. The post-peak behaviour shows some ductility, which results from the capacity of the walls in sustaining the load while the shear crack opens gradually. This behaviour is attributed to the friction generated in the crack, while the pre-peak behaviour was mainly due to the cohesion provided by the geopolymeric binder.

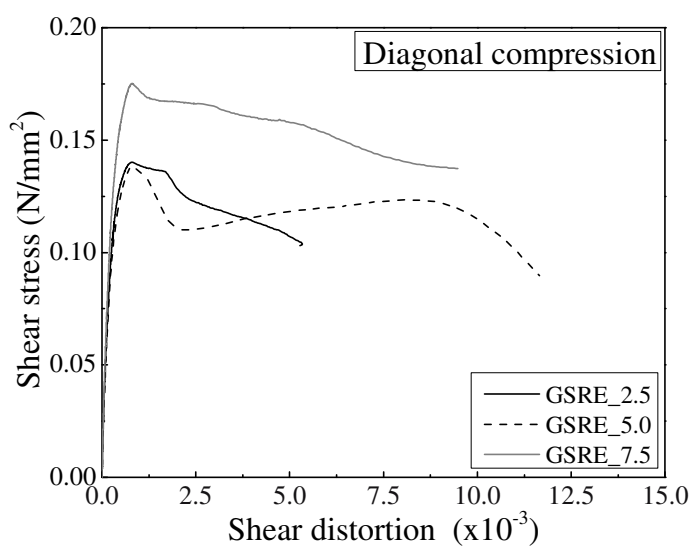

Fig. 11 - Shear stress-shear distortion curves of wallets.

The formation of a shear crack was responsible for the failure of the specimens, whose onset occurred before their respective peak loads being achieved. The failure mode is characterized by splitting of specimens caused by the shear crack (see Fig. 12). The formation of cracks in the layers' interfaces was observed in the post-peak phase, evidencing lack of adhesion across the compaction plane, which is as feature that can be improved in the manufacturing process. 


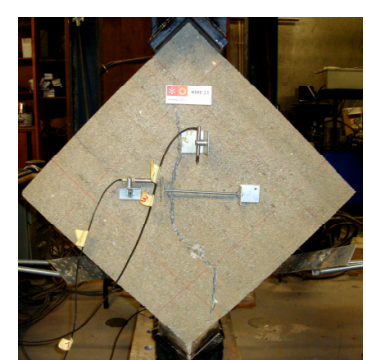

(a)

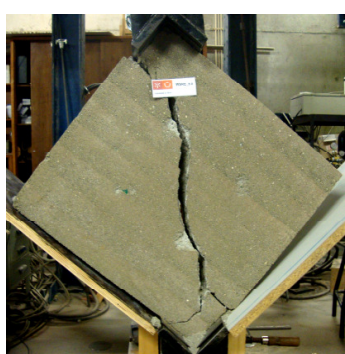

(b)

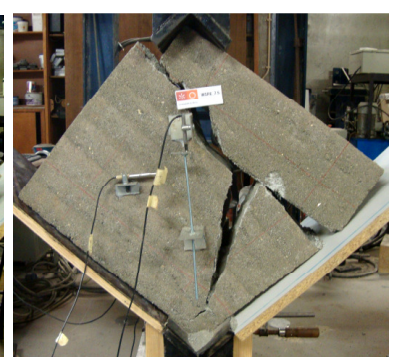

(c)

Fig. 12 - Failure mode of the wallets: (a) GSRE_2.5; (b) GSRE_5.0; (c) GSRE_7.5.

\subsubsection{Spray test (durability)}

Since the stabilisation of rammed earth should also improve the performance against water erosion, it was decided to perform the spray test, which is more aggressive than the Geelong test. The spray test was carried out on three specimens (of each composition), consisting of three-layered cubes of dimensions 200x200x200 $\mathrm{mm}^{3}$. The specimens were cured in wrapped plastic at room temperature of about $20 \pm 2^{\circ} \mathrm{C}$ for 28 days, after which were tested according to the procedure described in NZS 4298 [5], but only the pitting depth was measured. In addition to the SRE specimens, one URE specimen was also tested.

The results are presented in Table 11 and illustrated in Fig. 13. The SRE specimens did not present any evidence of erosion one hour after the start of the test, whereby erodibility index corresponds to 1 . On the other hand, the URE specimen presented a high level of erosion after only just 4 min of testing (see Fig. 13a) and it was completely washed out before the test was finished. The erodibility index of this specimen corresponds to 5, which confirms the higher harshness of this test when compared with the Geelong test. It is clear that the stabilisation using alkaline activation greatly improves the durability of rammed earth build with GRS.

Table $11-$ Results of the spray tests.

\begin{tabular}{lll}
\hline Mixture & Pitting depth $(\mathrm{mm})$ & Erodibility index \\
\hline URE & Washed out & 5 \\
GSRE_2.5 & 0 & 1 \\
GSRE_5.0 & 0 & 1 \\
GSRE_7.5 & 0 & 1 \\
\hline
\end{tabular}

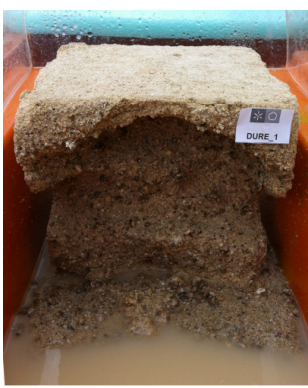

(a)

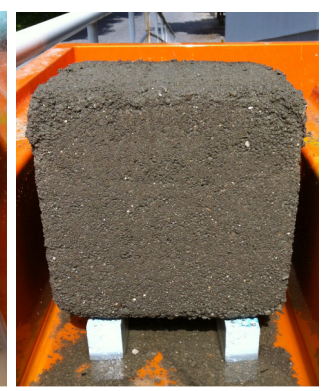

(b)

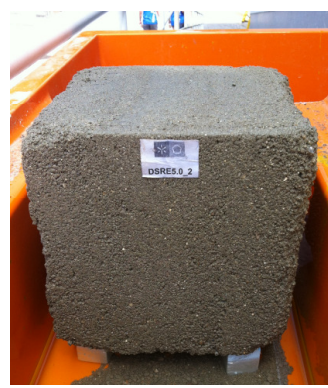

(c)

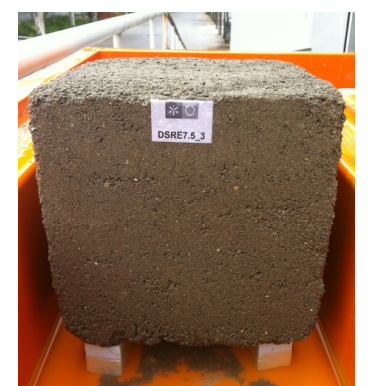

(d)

Fig. 13 - Spray tests: (a) URE specimen after 4 min of testing (b); GSRE_2.5 specimen after $1 \mathrm{~h}$ of testing; (c) GSRE_5.0 specimen after $1 \mathrm{~h}$ of testing; (d) GSRE_7.5 specimen after $1 \mathrm{~h}$ of testing. 


\subsection{Remarks}

The alkaline activation of fly ash was tested as a stabilisation solution for rammed earth construction with GRS, by assessing the performance of SRE specimens manufactured with soil S3. All tested compositions were able to improve the compressive strength, but failed at fulfilling requirements of regulating documents. This low mechanical performance can be explained by three main reasons: (i) insufficient polymeric binder; (ii) short curing period; (iii) compaction features not being optimized for each mixture. The shear behaviour of walletspecimens was also assessed, from which it was stated that this stabilisation technique results in shear strengths rather high when compared with results from the bibliography relative to URE and adobe. Regarding the performance against water erosion, the geopolymeric binder promoted an exceptional result by reducing the spray test pitting depth to zero.

\section{CONCLUSIONS}

The experimental research developed is presented as two sequential parts; the first assesses the suitability of GRS for URE construction, while the second tests the alkaline activation of fly ash as a stabilisation solution for SRE with GRS.

The suitability of four GRS for URE was first assessed by characterizing the soils, resorting to expeditious and laboratory tests, and then by testing the performance of URE specimens manufactured with them. In the first case, it was shown that soils S1, S2 and S3 do not meet characteristics that allow considering them as suitable; despite some conflicts found between the consulted documents, regarding the PSD. In opposition, soil S4 represents GRS of higher clay content, which leads to consider it as suitable. However, the assessment of the performance of manufactured URE specimens showed that minimum compressive strength requirements are not meet for any soil, where, in fact, the average compression strength was inferior to $0.5 \mathrm{~N} / \mathrm{mm}^{2}$. This means that the assessment of the soil suitability for URE only based on properties of the soil may produce misleading judging. Therefore, it is advisable to take into account always an approach based on the performance assessment. Considering the obtained results and the typical properties of GRS from northern Portugal (low clay percentages, constituted mainly by low activity clay minerals - kaolinite) it can be said that these soils are, in general, unsuitable for URE, and thus their use seems to be limited to SRE. The alkaline activation of fly ash was then tested as an alternative stabilisation solution of low environmental impact, by assessing the performance of SRE specimens manufactured with soil S3; three compositions, incorporating $2.5 \%, 5 \%$ and $7.5 \%$ fly ash, were studied. The 
performance improvement was mainly reflected on the durability, since the pitting depth of the spray test was reduced to zero. The compressive strength improvement by the tested compositions was not satisfactory to meet minimum requirements. This poor result raised questions that must be addressed in further investigation, namely: (i) incorporation of higher fly ash percentages; (ii) time evolution of the strength; (iii) and compaction optimization of mixtures of soil and fly ash geopolymer. Nevertheless, the stabilisation of GRS by alkaline activation of fly ash showed indications that, at a more mature development stage, it will allow SRE to be used in northern Portugal and in other places where soils with similar characteristics are available, while maintaining the ambient-friendly perspective of building with earth.

\section{Acknowledgements}

The authors wish to express their gratitude to Direct Pedra Lda for providing the required quantities of soil S3 and to Helena Faria for the assistance in the laboratory tests.

\section{References}

[1] Houben H, Guillaud H. Earth Construction: A Comprehensive Guide. Intermediate Technology Development Group; 2008.

[2] http://historicrammedearth.com/one-third-of-worlds-population-live-in-earth-buildings/ (19/03/2013)

[3] Bui QB, Morel JC, Hans S, Meunier N. Compression behaviour of non-industrial materials in civil engineering by three scale experiments: the case of rammed earth, Mater Struct 2008; 42(8): 1101-1116; 2008.

[4] Standards New Zealand. Engineering design of earth buildings (NZS 4297:1998). Standards New Zealand, Wellington; 1998.

[5] Standards New Zealand. Materials and workmanship for earth buildings (NZS 4298:1998). Standards New Zealand, Wellington; 1998.

[6] Standards New Zealand. Earth buildings not requiring specific design (NZS 4299:1998). Standards New Zealand, Wellington; 1998.

[7] SENCICO. Reglamento Nacional de Construcciones (NTE E 0.80 Adobe). SENCICO, Lima; 2006.

[8] NMRLD. Housing and Construction: Building Codes General: New Mexico Earthen Building Materials Code (NMAC 14.7.4). New Mexico Regulation and Licensing Department, New Mexico; 2000.

[9] Pacheco-Torgal F, Jalali S. Earth construction: lessons from the past for future eco-efficient construction. Constr Build Mater 2012;29:512-519.

[10] Lourenço PI. Earth constructions. Msc. thesis, Instituto Superior Técnico (IST), Portugal; 2002.

[11] Correia M. Fortificações islâmicas em taipa militar. Pedra \& Cal 2004;24:16. 
[12] Correia M, Merten JA. Taipa Alentejana - Sistemas Tradicionais de Protecção. IV Seminário IberoAmericano de Construção com Terra e III Seminário Arquitectura de Terra em Portugal 2005, Monsaraz.

[13] Pinto J, Varum H, Cruz D, Sousa D, Morais P, Tavares P et. al. Characterization of traditional tabique constructions in Douro North Valley region. WSEAS Transactions on Environment and Development 2010;6 (2):93-102.

[14] Tellado M. Construcciones de tapia en la tierra de Lemos, Proceedings of Segundo Congreso Nacional de Historia de la construcción 1998, Coruña.

[15] Viana da Fonseca A. Geomecânica dos solos residuais do granito do Porto. Critérios para dimensionamento de fundações directas. PhD Thesis, Dept. of Civil Engineering, University of Porto, Portugal; 1996.

[16] Escobar MC. Rammed earth: feasibility of a global concept applied locally. Msc. thesis, University of Minho, Portugal, 2011.

[17] Delgado M, Guerrero I. The selection of soils for unstabilised earth building: A normative review, Construction and building materials 2007;21(2):237-351

[18] ASTM. Standard Practice for Description and Identification of Soils (Visual-Manual Procedure) (ASTM D2488). American Society for Testing and Materials, West Conshohocken, PA; 2000.

[19] Standards Australia. The Australian earth building handbook (HB 195). Standards Australia, Sydney; 2002.

[20] LNEC. Análise granulométrica (LNEC E196). Laboratório Nacional de Engenharia Civil, Lisbon; 1966.

[21] Norma Portuguesa NP 143. Solos: determinação dos limites de consistência. Portugal; 1969.

[22] ASTM Standard Test Method for Shrinkage Factors of Soils by the Wax Method (ASTM D4943). American Society for Testing and Materials, West Conshohocken, PA, 1995.

[23] LNEC. Ensaio de compactação (LNEC E197). Laboratório Nacional de Engenharia Civil, Lisbon; 1967.

[24] LNEC. O uso da terra como material de construção. Laboratório Nacional de Engenharia Civil, Lisbon; 1953.

[25] ASTM. Standard Practice for Classification of Soils for Engineering Purposes (Unified Soil Classification System) (ASTM D2487). American Society for Testing and Materials, West Conshohocken, PA; 2000.

[26] Doat P, Hays A, Houben H, Matuk S, Vitoux F. Building with earth. The Mud Village Society, New Delhi, 1991.

[27] Lax C. Life cycle assessment of rammed earth. Msc. thesis, University of Bath, United Kingdom; 2010.

[28] Shi C, Roy D, Krivenko P. Alkali-activated cements and concrete. London: Taylor \& Francis Ltd.; 2006

[29] Pacheco-Torgal F, Castro-Gomes J, Jalali S. Alkali-activated binders: A review. Part 2. About materials and binders manufacture. Constr Build Mater 2008;22:1315-1322.

[30] Cristelo N, Glendinning S, Teixeira Pinto A. Deep soft soil improvement by alkaline activation. Proc ICE - Ground Improv 2011;164:73-82.

[31] Cristelo N, Glendinning S, Fernandes L., Teixeira Pinto A. Effect of calcium content on soil stabilisation with alkaline activation. Const Build Mater 2012; 29:167-174.

[32] Cristelo N, Glendinning S, Miranda T, Oliveira DV, Silva RA. Soil stabilisation using alkaline activation of fly ash for self compacting rammed earth construction. Constr Build Mater 2012; 36:727-735. 
[33] Cristelo N, Glendinning S, Fernandes L, Teixeira Pinto A. Effects of Alkaline-activated fly ash and Portland cement on soft stabilisation. Acta Geotechnica 2012. DOI 10.1007/s11440-012-0200-9.

[34] ASTM. Standard Test Method for Diagonal Tension (Shear) in Masonry Assemblages (ASTM E519). American Society for Testing and Materials, West Conshohocken, PA; 2002.

[35] Lacouture L, Bernal C, Ortiz J, Valencia D. Estudios de vulnerabilidad sísmica, rehabilitación y refuerzo de casas en adobe y tapia pisada. Apuntes 2007;20(2):286-303.

[36] Varum H, Silveira D, Carvalho J, Figueiredo A, Costa A. Caracterização do comportamento mecânico de paredes de alvenaria de adobe. Construcción com tierra. Tecnologia y Arquitectura. Congresso de tierra en Cuenca de Campos 2011, Valladolid:225-228. 


\section{LIST OF TABLE CAPTIONS}

Table 1 - Expeditious and laboratory tests used to characterize the GRS soils.

Table 2 - Particles size fractions of the assessed soils (according to the size fractions usually adopted in earth construction).

Table 3 - Atterberg's limits of the soils and respective USCS classification.

Table 4 - Compaction properties of the soils and compaction water content obtained by drop test (DTWC).

Table 5 - Average results of the compression tests carried out on URE specimens.

Table 6 - Required compressive strength according to documents regulating rammed earth construction.

Table 7 - Results of the Geelong test.

Table 8 - Composition of the tested mixtures.

Table 9 - Average results of the compression tests on SRE specimens.

Table 10 - Results of the diagonal compression tests.

Table 11 - Results of the spray tests. 


\section{LIST OF FIGURE CAPTIONS}

Fig. 1 - Rammed earth construction in Portugal: (a) geographical distribution; (b) new rammed earth house with embedded concrete structure (Odemira, Portugal).

Fig. 2 - Sedimentation test: (a) soil S2 sedimentation flask; (b) results of all tests.

Fig. 3 - Ribbon test: (a) soil S1; (b) soil S4.

Fig. 4 - Possible states of the ball after impact: (a) crumble partly with minor cracks, (b) completely crumbled; (c) flattened.

Fig. 5 - Dry strength test.

Fig. 6 - Comparison between the PSD curves of the soils and the envelope presented by Viana da Fonseca [15] for GRS from northern Portugal.

Fig. 7 - Comparison between the PSD curves of the soils and the envelopes for rammed earth construction recommended by: (a) Houben and Guillaud [1]; (b) Portuguese National Laboratory of Civil Engineering [24].

Fig. 8 - Compression tests: (a) test setup; (b) LVDTs configuration.

Fig. 9 - Geelong test: (a) test setup; (b) pitting depth; (c) depth of moisture penetration of soil specimen S2.

Fig. 10 - Tests carried out on SRE specimens: (a) compression test; (b) diagonal compression test; (c) spray test.

Fig. 11 - Shear stress-shear distortion curves of wallets.

Fig. 12 - Failure mode of the wallets: (a) GSRE_2.5; (b) GSRE_5.0; (c) GSRE_7.5.

Fig. 13 - Spray tests: (a) URE specimen after 4 min of testing (b); GSRE_2.5 specimen after 1h of testing; (c) GSRE_5.0 specimen after 1h of testing; (d) GSRE_7.5 specimen after 1h of testing. 